\title{
Urinary N-Acetyl-Beta-D-Glucosaminidase Index Activity Normal Values in Healthy Wistar Rats
}

\author{
Andrei Răzvan CODEA ${ }^{1}$, Mircea MIRCEAN ${ }^{1 *}$, Orsolya SARPATAKI ${ }^{3}$, Bogdan SEVASTRE ${ }^{3}$, Gavril GIURGIU ${ }^{1}$ \\ Cristian POPOVICI ${ }^{1}$, Iuliu SCURTU ${ }^{1}$, Daniela NEAGU ${ }^{1}$, Liviu OANA ${ }^{2}$ \\ ${ }^{1}$ Department of Internal Medicine, University of Agricultural Sciences and Veterinary Medicine, Cluj- \\ Napoca, Romania; \\ ${ }^{2}$ Department of Surgical Propaedeutics, University of Agricultural Sciences and Veterinary Medicine, Cluj- \\ Napoca, Romania; \\ ${ }^{3}$ Department of Patophisiology, University of Agricultural Sciences and Veterinary Medicine, Cluj-Napoca, \\ Romania: \\ *corresponding author: mircea.mircean@usamvcluj.ro
}

Bulletin UASVM Veterinary Medicine 75(1)/2018

Print ISSN 1843-5270; Electronic ISSN 1843-5378

doi:10.15835/buasvmcn-vm:005817

\begin{abstract}
Reference values have a major importance in describing the diversity of healthy individuals variables. These are population reference ranges (RIs) that comprise $95 \%$ of the healthy population. The determination of biological markers, like urinary NAG and creatinine, is considered a simple, rapid and non-invasive method for detecting and monitoring renal tubular function under different conditions. Calculation of the urinary NAG index provides a good estimate of the excretion of the two markers over a 24 hour period. An increase of the urinary NAG index may precede increases in standard parameters used in the diagnosis of renal disease, especially in cases of acute tubular lesions. With the purpose of detecting deviations of the urinary NAG index, this study established the reference values in Wistar rats. Urine samples were collected from 100 healthy Wistar rats, 50 males and 50 females. NAG and creatinine were determined, and subsequently the NAG index was calculated for reference value establishing. The mean value of NAG index was found to be $5.81 \pm 1.68$ (U / g) for healthy females and $4.10 \pm 0.90$ (U / g) for healthy males.
\end{abstract}

Keywords: reference values, urinary NAG index, Wistar rat

\section{Introduction}

Increases in NAG index may precede increases in standard parameters used in the diagnosis of kidney disease, especially in cases of acute tubular lesions (Csáthy et al., 1994; Spasovski., 2013). The intensity of urinary excretion of kidney tissue enzymes, especially NAG, could act as an indicator of kidney disease and may even precede other symptoms of renal injury (Ellis et al., 1975; Sato et al., 2002). N-acetyl-beta-D-glucosaminidase (NAG) is a lysosomal enzyme present in proximal tubular cells (Vanderlinde et al., 1981). An increased NAG urinary excretion could serve as an indicator of tubular lesions due to ischemia, inflammation and intoxication or other types of kidney disorders such as urinary tract infections, vesicoureteral reflux, diabetes mellitus, nephrotic syndrome, glomerulonephritis, nephrocalcinosis, hypercalciuria, urolithiasis, hypertension, hypoxia, heavy metal intoxication, nephrotoxic drug therapy, and heart failure (Aato et al., 2002; Feldman et al., 1989; Sato et al., 2002). Recent studies have shown that urinary NAG has been reported as a sensitive predictor of chronic renal disease (Kwiatkowska et al., 2014).

Reference values are one of the most solid tools of laboratory medicine with a role in clinical decision making (Grasbeck et al., 1983). 
Table 1. Creatinine, NAG, NAG index values in Wistar rats (mean values \pm standard deviation)

\begin{tabular}{cccc}
\hline Parameters & Male $(\mathrm{n}=50)$ & Female $(\mathrm{n}=50)$ & TOTAL $(\mathrm{n}=100)$ \\
\hline Creatinine $(\mathrm{g} / \mathrm{l})$ & $1.30 \pm 0.26$ & $1.03 \pm 0.28$ & $1.16 \pm 0.30$ \\
\hline NAG(U/l) & $5.18 \pm 0.77$ & $5.62 \pm 0.47$ & $5.42 \pm 0.66$ \\
\hline NAG index $(\mathrm{U} / \mathrm{g})$ & $4.10 \pm 0.90$ & $5.81 \pm 1.68$ & $4.95 \pm 1.59$ \\
\hline
\end{tabular}

Our study aimed to determine the NAG index in clinically healthy Wistar male and female rats.

\section{Materials and methods}

The experiment was performed according to the European Communities Council Directive $(63 / 2010)$ and the national legislation $(43 / 2014)$ and authorized by the Bioethical Board of the Faculty of Veterinary Medicine, Cluj-Napoca. The animals were housed in polycarbonate cages, at a controlled temperature $\left(21-22^{\circ} \mathrm{C}\right)$, humidity (40$60 \%$ ) and $12 / 12 \mathrm{~h}$ light/dark cycle. Standard lab chow, provided by National Institute for Research and Development Cantacuzino Bucharest, and water were freely available.

The experiment was carried out on 100 albino Wistar rats (50 females and 50 males) with 250300 g body weight.

Urine samples $(n=100)$ were collected in Eppendorf tubes by applying a slight pressure to the hind limbs of each rat. Urine was centrifuged at $900 \mathrm{rpm}$ for $5 \mathrm{~min}$ at $4{ }^{\circ} \mathrm{C}$, and the supernatant was collected for subsequent determinations. All determinations were performed in less than 6 hours after sampling (Noto et al., 1983; Sato et al., 2002).

Enzymatic activity of NAG was determined at $37^{\circ} \mathrm{C}$ using a commercial available kit (Diazyme Lab, CA, USA). This commercial kit contains three reagents: R1-MNP-GlcNAc and $\mathrm{HCl}, \mathrm{R} 2$-Citric Acid and Potassium Phosphate, R3-Sodium Carbonate (Buffer). The principle of the method is based on the ability of the NAG to hydrolyze 2-methoxy-4(2'-nitrovinyl) -phenyl 2-acetamido-2-deoxy- $\beta$ D-glucopyranoside (MNP-GlcNAc) (2'-nitrovinyl) -phenol, its formation being determined using a spectrophotometer (Hospitex Diagnostics, Italy) set at $505 \mathrm{~nm}$ wavelength. Urine NAG concentration was expressed in $\mathrm{U} / \mathrm{l}$.

Urinary concentration of creatinine was determined by a fixed-time colorimetric reaction using a commercial kit with two reagents: R1-Picric Acid and R2-Sodium Hydroxide and Disodium
Phosphate. The method is based on the Jaffe Reaction, and consists of the formation of the color complex between creatinine and alkaline picrate at $37^{\circ} \mathrm{C}$. Reading was performed after calibration of the spectrophotometer at wavelength $515 \mathrm{~nm}$. The results were expressed in $\mathrm{g} / \mathrm{l}$.

Results of the urinary NAG and creatinine determinations were subsequently used to calculate the NAG Index based on the following formula (Sato et al., 2002):

$$
\text { Index NAG }(\mathrm{U} / \mathrm{g})=\frac{\mathrm{NAG}(\mathrm{U} / \mathrm{g})}{\text { Creatinine }(\mathrm{g} / \mathrm{l})}
$$

Data was expressed as mean \pm standard deviation (SD). Median values were compared using Student-t test. All statistical calculations were performed using Microsoft Excel 2010.

\section{Results and discussions}

Basic descriptive data regarding the observed parameters are presented in Table 1 . Urinary creatinine had a higher value in male rats $(1.30 \pm 0.26 \mathrm{~g} / \mathrm{l})$ then in females $(1.03 \pm 0.28 \mathrm{~g} / \mathrm{l})$. Female rats demonstrated a higher NAG ranging from $3.62 \mathrm{U} / \mathrm{g}$ to $8.85 \mathrm{U} / \mathrm{g}$, compared to males (3.18 -7.52 U/g), consequently NAG index values were higher in clinically healthy female Wistar rats.

Following the statistical analysis, by performing the t-test: Two-Sample Assuming Equal Variances, it was found that with respect to creatinine and NAG, the resulting gender values did not differ significantly, namely P \& lt; 0.05 in the case of Creatinine, and $\mathrm{p}<0.02$ for NAG. Following the analysis of the gender NAG index values for Wistar rats, it was found that they had differences with a high statistical relevance $\mathrm{p}<0.002$.

The median NAG index value was found to be $4.95 \pm 1.59 \mathrm{U} / \mathrm{g}$ in healthy Wistar rats $(\mathrm{n}=100)$ with significant differences between males and females $(p<0.002)$, mean values between males and females showed an average difference of 0.82 $\mathrm{U} / \mathrm{g}$. 
Because of the significant differences in urinary NAG index values between males and females, separate reference values should be used for interpretation. The minimum value, $3.18 \mathrm{U} / \mathrm{g}$, was found in sample 22 (male) and the maximum value, $8.85 \mathrm{U} / \mathrm{g}$ was found in sample 9 (female).

\section{Conclusions}

The mean NAG index value of the entire group of rats $(\mathrm{n}=100,50=\mathrm{F}, 50=\mathrm{M})$ is $4.95 \pm 1.59$ (U / g). The mean NAG index recorded in the urine of Wistar females was $5.81 \pm 1.68$ (U / g). The mean NAG index recorded in the urine of Wistar male males was $4.10 \pm 0.90(\mathrm{U} / \mathrm{g})$. Urinary NAG index values was found to be higher in female rats compared to male rats $(5.81 \pm 1.68$ vs. $4.10 \pm 0.90$ $\mathrm{U} / \mathrm{g}$ ), with an average difference of $0.82(\mathrm{U} / \mathrm{g})$.

Acknowledgments. This research did not receive any specific grant from funding agencies in the public, commercial, or not-for-profit sectors.

\section{References}

1. Csáthy L, Oláh AV, Pócsi I, Varga J, Balla G, Price RG (1994). Age-dependent urinary $\mathrm{N}$-acetyl-beta-Dglucosaminidase activity in healthy children. Orvosi Hetilap, 135: 13011303.

2. Ellis BG, Tucker SM, Thompson AG, Price RG (1975). Presence of serum and tissue forms of N-acetyl-3-Dglucosaminidase in urine from patients with renal disease. Clinica Chimica Acta, 64: 195-202.
3. Feldmann D, Flandrols C, Jardel A, MInhPhan T, Aymard $P$ (1989). Circadian variations and reference intervals for some enzymes in urine of healthy children. Clinical Chemistry, 35: 864-867.

4. Grasbeck R (1983). Reference value philosophy. Bulletin of Experimental Biology and Medicine, 8: 1-11.

5. Henny J, Hyltoft P (2004). Reference values: from philosophy to a tool for laboratory medicine. Clinical Chemistry and Laboratory Medicine, 42: 686-691.

6. Kwiatkowska E, Leszek D, Bober J, Kłoda K, Safranow K, Szymańska-Pasternak J, Romanowski M, Sulecka A, Pawlik A, Ciechanowski K (2014). N-acetyl-betaglucosaminidase urine activity as a marker of early proximal tubule damage and a predictor of the long-term function of the transplanted kidneys. The Journal of the Polish Biochemical Society and of the Committee of Biochemistry and Biophysics, 61: 275-280.

7. Noto A, Ogawa $\mathrm{Y}$, Mori S, Yoshioka M, Kitakaze T, Hori T, Nakamura M, Miyake T (1983). Simple, rapid spectrophotometry of urinary N-acetyl-beta-Dglucosaminidase, with use of a new chromogenic substrate. Clin Chem, 29: 1713-1716.

8. Sato R, Soeta S, Miyazaki M, Syuto B, Sato J, Miyake Y, Yasuda J, Okada K, Naito Y, (2002). Clinical availability of urinary $\mathrm{N}$-acetyl-beta-D-glucosaminidase index in dogs with urinary diseases. The Journal of Vetrinary Medical Science, 64: 361-365.

9. Spasovski D (2013). Renal markers for assessment of renal tubular and Glomerular dysfunction. Journal of Nephropharmacology, 2: 23-25.

10. Vanderlinde RE (1981). Urinary enzyme measurements in the diagnosis of renal disorders. Annals of Clinical and Laboratory Science, 11:191-201. 